\title{
QUEEN'S
UNIVERSITY
BELFAST
}

\section{Practical guidelines for physicians in promoting oral health in frail older adults}

Kossiono, A. E., Hajto-Bryk, J., Janssens, B., Maggi, S., Marchini, L., McKenna, G., Muller, F., Petrovic, M., Roller-Wirnsberger, R. E., Schimmel, M., van der Putten, G. J., Vanobbergen, J., \& Zarzecka, J. (2018). Practical guidelines for physicians in promoting oral health in frail older adults. Journal of the American Medical Directors Association, 19(12), 1039-1046. https://doi.org/10.1016/j.jamda.2018.10.007

Published in:

Journal of the American Medical Directors Association

\section{Document Version:}

Peer reviewed version

\section{Queen's University Belfast - Research Portal:}

Link to publication record in Queen's University Belfast Research Portal

\section{Publisher rights}

Copyright 2018 AMDA. Published by Elsevier.

This manuscript is distributed under a Creative Commons Attribution-NonCommercial-NoDerivs License

(https://creativecommons.org/licenses/by-nc-nd/4.0/), which permits distribution and reproduction for non-commercial purposes, provided the author and source are cited.

\section{General rights}

Copyright for the publications made accessible via the Queen's University Belfast Research Portal is retained by the author(s) and / or other copyright owners and it is a condition of accessing these publications that users recognise and abide by the legal requirements associated with these rights.

Take down policy

The Research Portal is Queen's institutional repository that provides access to Queen's research output. Every effort has been made to ensure that content in the Research Portal does not infringe any person's rights, or applicable UK laws. If you discover content in the Research Portal that you believe breaches copyright or violates any law, please contact openaccess@qub.ac.uk. 


\section{Practical guidelines for physicians in promoting oral health in frail older adults}

Anastassia E. Kossioni DDS, MSC, PhD a,c, ${ }^{*}$, Justyna Hajto-Bryk DDS, PhD a,d, Barbara Janssens MDS, PhD a,e ,Stefania Maggi MD, MPH, PhD b,f, Leonardo Marchini DDS MSD, PhD a,g, Gerry McKenna BDS, FDS, PhD a,h, Frauke Müller Dr med dent habil a,i, Mirko Petrovic MD, PhD ${ }^{\mathrm{b}, \mathrm{j}}$, Regina Elisabeth Roller-Wirnsberger MD, MME ${ }^{\mathrm{b}, \mathrm{k}}$, Martin Schimmel Dr med dent habil, MAS Oral Biola,l, Gert-Jan van der Putten MD, $\mathrm{PhD}{ }^{\mathrm{a}, \mathrm{m}}$,Jacques Vanobbergen MDS, $\mathrm{PhD}^{\mathrm{a}, \mathrm{e}}$, Joanna Zarzecka $\operatorname{Dr}$ hab $\mathrm{n}$ med ${ }^{\mathrm{a}, \mathrm{d}}$

a for the European College of Gerodontology

${ }^{b}$ for the European Geriatric Medicine Society

c Division of Gerodontology, Department of Prosthodontics, School of Dentistry, National and Kapodistrian University of Athens, Greece

d Institute of Dentistry, Faculty of Medicine, Jagiellonian University Medical College, Kraków, Poland

e Community Dentistry and Oral Public Health, Dental School, Ghent University, Ghent, Belgium

${ }^{f}$ CNR Neuroscience Institute, Aging branch, Padova, Italy

9 Department of Preventive and Community Dentistry, College of Dentistry and Dental Clinics, The University of lowa, lowa City, IA, USA

${ }^{\mathrm{h}}$ Centre for Public Health, Royal Victoria Hospital, Queens University Belfast, Northern Ireland

' Division of Gerodontology \& Removable Prosthodontics, University Clinics of Dental Medicine, University of Geneva, Geneva, Switzerland

J Department of Internal Medicine (Geriatrics), Faculty of Medicine and Health Sciences, Ghent University, Belgium

K Department of Internal Medicine, Medical University of Graz, Austria

' Division of Gerodontology, School of Dental Medicine, University of Bern, Switzerland

m Radboud University Medical Center, Nijmegen, The Netherlands Department of Oral Function and Prosthetic Dentistry Nijmegen, The Netherlands

${ }^{*}$ Corresponding author: $\operatorname{Dr}$ Anastassia Kossioni, Dental School, National and Kapodistrian University of Athens, Greece, tel. +302107461206, email: akossion@dent.uoa.gr 


\section{Abstract}

Good oral health in old age is particularly important for maintaining adequate oral function, preventing pain and discomfort, controlling localized or systemic inflammation, sustaining social interaction and preserving quality of life. Given that oral health is an integral part of general health and well-being, and that major chronic systemic and oral diseases share common risk factors, oral health prevention and promotion should be embedded within routine medical assessment and care provision. The role of medical physicians, particularly primary care physicians, geriatricians and elderly care physicians, in community and long-term care facilities in assessing and promoting oral health in frail older adults is critical and has been emphasized in recent European recommendations. All physicians should appreciate the importance of oral health and incorporate an initial oral health screening into routine medical assessment and care. A short interview with patients and carers on current oral health practices may help to assess the risk for rapid oral health deterioration. The interview should be followed by an oral health assessment, using validated tools, for non-dental health care providers. Based on these findings the physician should decide on necessary follow-up procedures which may include oral health counseling and/or dental referral. Oral health counseling should include advice on daily oral, mucosal and denture hygiene, denture maintenance, dietary advice, smoking cessation, limitation of harmful alcohol consumption, management of xerostomia and frequent dental review. To enable physicians to perform the tasks recommended in this publication appropriate teaching at both undergraduate and postgraduate levels must be delivered in addition to provision of appropriate continuing education courses. 


\section{Introduction}

The "World Report on Ageing and Health" by the World Health Organisation $(\mathrm{WHO}){ }^{1}$ stated that "Oral health is a crucial and often neglected area of healthy ageing". Oral diseases constitute a major public health challenge particularly amongst poor, disadvantaged and socially marginalized older people, who bear a disproportionate burden of pain, and impaired function in swallowing, eating, tasting, smiling, and communicating. ${ }^{1,2}$ Frail older adults have poorer oral health compared to their functionally independent counterparts. ${ }^{2}$ Adequate oral health in old age is particularly important not only for maintaining adequate oral function but also for maintaining social interaction, self-esteem, quality of life and personal dignity. ${ }^{2-4}$ Given that oral health is an integral part of general health and well-being, and that major chronic and oral diseases share common risk factors, ${ }^{1,2}$ it is crucial that all health professionals identify and prevent common oral conditions in the population ${ }^{5,6}$ and particularly in frail and caredependent older adults. ${ }^{7}$

The European College of Gerodontology (ECG) and the European Geriatric Medicine Society (EuGMS) have recently published policy recommendations on improving oral health in older adults, particularly in frail and care-dependent elders with limited access to dental care. ${ }^{7}$ These recommendations stress the value of multidisciplinary collaboration, and integration of oral health screening into routine medical assessment and care. Among the suggested action plans were the development of appropriate legislation, guidelines and protocols for oral health prevention and promotion in community and institutional facilities (i.e. rehabilitation centres, long-term care hospitals, assisted living, residential 
care and nursing homes) and the education of non-dental healthcare providers in oral health assessment based on clearly described competencies. These competencies include: being able to appreciate the importance of oral health for general health, wellbeing and quality of life, assessing and adapting medication use to protect oral health, performing an initial oral health assessment, identifying enabling and disabling factors (such as behaviour and attitude of the patient and / or cage-givers) regarding maintaining daily oral care, identifying common oral conditions and habits in older adults, appropriate referral to dental professionals, offering preventive oral health counseling to patients and carers, and communicating oral health findings and interventions to the other members of the health care team. ${ }^{7}$

The aim of this document is to describe practice guidelines and clinical tools for physicians, particularly primary and elderly care physicians, and geriatricians, for promoting oral health in frail and care-dependent older adults, based on the competencies previously described in the European recommendations. ${ }^{7}$

\section{The association of oral health with general health in older adults}

A growing body of evidence has revealed a number of significant associations between oral health and general health. In particular, a number of systematic reviews, meta-analyses and consensus reports have shown significant associations between periodontal disease, and atherosclerotic vascular disease (ASVD), ${ }^{8-11}$ diabetes mellitus, mainly type 2,9,12 and aspiration pneumonia. ${ }^{13}$ Periodontal disease is a chronic inflammation caused by microorganisms in the dental biofilm causing a progressive destruction of the tooth supporting tissues. The disease starts usually early in life and is very common in old age. It is considered one of the leading causes of tooth loss. 
Periodontal disease is significantly associated with ASVD, particularly in middle age, but it is still unclear if there is any causative involvement as the two diseases share many common risk factors, such as age, cigarette smoking, and diabetes mellitus. ${ }^{10,11}$ There is moderate evidence that periodontal treatment reduces systemic inflammation as evidenced by reduction in C-reactive protein (CRP) and improvement of both clinical and surrogate measures of endothelial function, but more research is necessary. ${ }^{11}$ The American Journal of Cardiology and Journal of Periodontology Editors' Consensus recommended that periodontal evaluation should be considered in patients with ASVD who have signs or symptoms of gingival disease, significant tooth loss, and/or unexplained elevations of hsCRP or other inflammatory biomarkers. ${ }^{8}$ Both dentists and physicians should collaborate to optimize CVD risk reduction, including via periodontal therapy. ${ }^{8}$

Tooth loss, another common finding in old age, has been associated with carotid artery plaque prevalence ${ }^{14}$ and circulatory mortality, ${ }^{15}$ but more research is necessary to clarify these associations. Three potential biological mechanisms explaining the link between the number of teeth and mortality are inflammation, infection, and diet and nutrition. ${ }^{15}$ In addition, the social determinants of health may also present a common risk factor.

Also, a bi-directional association between periodontitis and type 2 diabetes has been reported. Periodontitis is associated with poorer glycaemic control among people with type 2 diabetes and patients with more severe periodontal disease face more severe diabetes complications; on the other hand poor glycemic control is associated with increased risk and severity of periodontitis. ${ }^{12}$ There is also evidence of a clinically meaningful reduction of $\mathrm{HbA} 1 \mathrm{C}$ levels in people 
with type 2 diabetes after periodontal therapy. ${ }^{16}$ Therefore, the International Diabetes Federation and the European Federation of Periodontology highlighted the role of medical health professionals in investigating the presence of periodontitis in patients with diabetes. ${ }^{12}$ The physician should ascertain that patients with diabetes are asked about signs and symptoms of periodontal disease and receive appropriate oral health education and periodontal care from a dentist when necessary. ${ }^{12}$

It should be noticed that periodontal care should start early, in order to prevent not only tooth loss, but also the potential effect of a cumulative systemic damage which may continue even after the teeth are lost due to severe periodontitis. $^{14}$

Periodontal pockets, poor oral hygiene and denture wearing during sleep have been associated with aspiration pneumonia, a leading cause of mortality in frail older population, especially when swallowing disorders are present. ${ }^{13,17}$ Respiratory pathogens are more frequently found in the mouth of older nursing homes residents compared to ambulatory patients. ${ }^{18}$ Findings from RCTs have shown that approximately one in 10 cases of death from pneumonia in elderly nursing home residents may be prevented by improving oral hygiene. ${ }^{18}$ Improved oral hygiene consisting of tooth brushing after each meal, cleaning dentures, once a day, and professional oral health care once a week, seems an effective intervention to reduce the incidence of aspiration pneumonia in hospitalized or institutionalized older people. ${ }^{19}$

Longitudinal data from the Kashiwa study in Japan has defined "oral frailty" as poor status in $\geq 3$ of the following indicators: number of natural teeth, chewing ability, articulatory oral motor skill, tongue pressure, and subjective difficulties 
in eating and swallowing, potentially leading to poor nutritional status. ${ }^{20}$ Oral frailty significantly predicted onsets of physical frailty, sarcopenia, need for longterm care and mortality. ${ }^{20}$ Further research on this association may identify specific oral health measures which prevent negative health outcomes in old age.

A number of reports indicate a bilateral association between nutrition, dietary intake and oral health. ${ }^{21,22}$ On one hand, oral health status (particularly natural tooth loss) may have implications for dietary intake and food choice, whilst on the other hand nutrition plays a key role in the aetiology of oral diseases such as caries and periodontal disease, which subsequently can cause difficulty in eating, thereby reducing the ability to consume a healthy diet. To break this vicious cycle, it has been recommended that an oral examination including a simple chewing performance test should be part of routine procedures for geriatric hospital admissions. ${ }^{23}$

Poor general condition in frail and care-dependent older adults increases the risk of rapid oral health deterioration (ROHD) due to physical and cognitive impairment impacting on daily oral hygiene. Patients with cognitive impairment $^{24}$, depression ${ }^{25}$ and manual dexterity issues ${ }^{26}$ (including parkinsonism and rheumatoid arthritis) usually face difficulties in maintaining appropriate oral hygiene regimes, elevating their risk for ROHD. Hyposalivation and xerostomia, often related to systematic medications, systemic diseases and head and neck radiotherapy further increase the ROHD risk, in turn causing dysphagia, dysgeusia, speaking and chewing problems, diminished taste, burning mouth, plaque accumulation, dental caries, periodontal disease, oral candidosis and denture-related lesions. ${ }^{27-30}$ 
Although oral and general health are significantly associated, few studies have investigated the knowledge and skills of primary care physicians to assess oral health and offer oral health counseling in older patients. The existing information indicates that oral health knowledge of physicians is not adequate, and a systematic oral health assessment for older people in primary care and in nursing homes is rarely performed. ${ }^{31,32} \mathrm{~A}$ study on incoming internal medicine trainees in New York revealed that the participants had inadequate knowledge regarding periodontal disease; $82 \%$ never asked their patients whether they were diagnosed with periodontal disease, $76 \%$ never screened their patients for periodontal disease, and $23 \%$ never referred patients to a dentist for evaluation and care. ${ }^{33}$

\section{Performing a patient interview on oral health practices and how to assess the risk for ROHD}

A patient/caregiver interview is an important tool to obtain oral health related information that helps formulate an individual diagnosis and treatment/maintenance plan. A system revision approach can reveal a number of relevant risk factors for ROHD among older adults. ${ }^{34}$ The most relevant risks are summarized as "7-Ds": Dementia, Depression, Dexterity, Drugs, Diabetes, Demotivation and Diet. However other individual risk factors can also affect ROHD such as hyposalivation caused by using continuous positive airway pressure (CPAP) for treatment of chronic obstructive pulmonary disease (COPD) or secondary to cancer treatment.

In order to provide a more accurate assessment of the risk for $\mathrm{ROHD}^{34}$ the authors propose the inclusion of six oral health-related questions in the patient/caregiver interview. The questions, the related risk of ROHD and the 
suggested follow-up are presented in Table 1. It should be noted that the responses to some of these questions require immediate oral examination and/or onward dental referral. However, as oral health problems in frail older people are often underreported and underdiagnosed, an initial oral examination is recommended for all patients.

\section{How to perform an initial oral health assessment and decide when to refer to a dentist}

Early diagnosis of oral pathology and oro-functional impairment can be undertaken by a physician who should refer appropriately selected patients for a detailed oral examination with a dentist. An oral examination should be part of each (geriatric) assessment and be included in the routine examination of head, ears, eyes, nose and throat. ${ }^{5,6}$

An initial oral health screening should be short, easy to perform, and be part of an examination tool that considers oral symptoms, normal anatomy and function, thus allowing for an appropriate diagnosis by the physician. The most common tools for initial oral screenings by non-dental healthcare providers are THROAT (The Holistic and Reliable Oral Assessment Tool) (see Supplementary Material), ${ }^{35}$ BOHSE (Brief Oral Health Status Examination) (see Supplementary Material), ${ }^{36}$ and its simplified version OHAT (Oral Health Assessment Tool) ${ }^{37}$ (Figure 1). Online training in using the OHAT may be accessed at: https://igec.uiowa.edu/gerialearning. These screening tools have demonstrated adequate validity and reliability and evaluate anatomical characteristics (lips, gums/gingiva, tissues/mucous membrane/palate/floor of mouth, tongue, natural teeth), as well as other important factors (saliva, oral 
cleanliness/smell, pain and presence of dentures). For each screening tool, individual examination categories receive a numerical score thus clearly indicating severe oral health problems and the need for onward dental referral. Amongst the most common chronic oral health conditions are caries (tooth decay) and periodontal disease (gum disease) which can both cause pain, discomfort and tooth loss as well as systemic complications. Caries is indicated by brown / black discoloration or cavities on the teeth and roots. Periodontal disease can be identified by red and swollen gums which bleed during tooth brushing, eating or spontaneously (Figure 2). Dental disease is often accompanied by accumulation of dental plaque or deposits covering the teeth (Figure 2). Patients presenting with caries and periodontal disease should receive initial counseling from the physician and be referred to a dentist for further treatment. Changes in colour, morphology and volume of other areas of the oral mucosa should be readily inspected by a dentist, as they can be related to infection, inflammation or oncology (Figure 3). Pain in the mouth, eating problems, dysphagia, and xerostomia/ hyposalivation can negatively impact oral function and quality of life and should also be reported to a dentist.

An assessment of chewing efficiency and eating ability in frail older people with sarcopenia, dysphagia or protein-energy malnutrition is very important. Apart from a simple recording of the number of teeth or occluding pairs of teeth, chewing efficiency should be measured using a simple two-colour chewing gum test with visual or, if possible, opto-electronical inspection. ${ }^{38}$

\section{Principles of oral disease prevention in older people}

Prevention of dental caries and periodontal disease 
Dental caries and periodontal disease represent the two most common reasons for natural tooth loss in old age. The prevalence of both diseases is high, with untreated dental caries being the most common chronic disease affecting humans worldwide. ${ }^{39}$ Prevention of periodontal disease (Figure 2) refers to reducing the development of clinically detectable gingival inflammation (gingivitis) that may ultimately progress to attachment and alveolar bone loss (periodontitis). Consistent evidence demonstrates that primary prevention strategies should be based on patient-performed control of the dental biofilm and routine professional mechanical plaque removal (PMPR) by the dental hygienist or the dentist. ${ }^{40}$ In addition, the control/management of common risk factors such as smoking and diabetes forms an important part of prevention of periodontal disease in which a physician can play an important role. In patients with diabetes the current evidence indicates that professional care accompanied by meticulous home care is both safe and effective. ${ }^{12}$

The most important risk factor for caries is the accumulation of a dental plaque biofilm which is then associated with tooth demineralisation. In older adults, exposed root surfaces are more vulnerable to demineralization than the coronal surfaces. Brushing with fluoride toothpaste at least twice a day is recommended. In individuals with high caries risk, root caries incidence, may decrease by changing a conventional toothpaste (1450 ppm fluoride) to a 5000 ppm fluoride toothpaste, when prescribed by a dentist ${ }^{41-43}$. For primary and secondary prevention of root caries lesions, a recent meta-analysis revealed that regular use of dentifrice containing 5000 ppm fluoride and quarterly professionally applied chlorhexidine or silver diamine fluoride varnishes may inactivate the existing and/or reduce the initiation of new root caries. ${ }^{42}$ Silver 
diamine fluoride has historically been used in young children with rampant "bottle caries", but is today no longer licensed in some countries. Nevertheless, an increasing number of publications support silver diamine fluoride use for root caries prevention and arrest in older populations, extending from those functionally independent with high to extreme caries risk to those highly dependent with limited access to care and increased caries risk. ${ }^{44}$ Chemical agents should be combined with meticulous dental hygiene and diet control to optimize the caries-controlling effect.

\section{Prevention of denture-related conditions}

Older patients with removable dentures may frequently suffer from denturerelated conditions such as denture stomatitis, denture hyperplasia, traumatic ulcers and poor denture fit. Oral candidosis is common in patients wearing dentures combined with hyposalivation and should be treated with topical/ or systemic antifungal agents and appropriate patient instructions on dentures' maintenance. Denture-related conditions may be prevented and treated by daily removal of bacterial biofilm from the dentures and the oral tissues, removal of dentures at night, and frequent dental visits to check dentures' fit and function..$^{45}$

\section{Prevention of hyposalivation and xerostomia (feeling of dry-mouth)}

As hyposalivation is a significant risk factor for dental caries and periodontal disease, relevant prevention strategies should be recommended. The physician should first assess the occurrence of hyposalivation and xerostomia. This may further require evaluation and modification of the patient's medication list by adding an equally effective, but less hyposalivation-inducing medication. In 
addition, the physician may need to manage any systemic diseases associated with hyposalivation and xerostomia (i.e. diabetes, Sjögren syndrome), control common side effects such as oral candidosis, and refer the patient to the dentist if necessary. The condition can be managed with non-pharmacological (see following paragraph) and pharmacological interventions (sialagogues such as pilocarpine, cevimeline, application of physostigmine to the oral mucosa, taking into consideration potential adverse-effects). ${ }^{28,46}$

\section{Prevention of oro-pharyngeal cancer}

The major risk factors for oro-pharyngeal cancer (Figure 3) are tobacco and excessive use of alcohol. ${ }^{47}$ As oro-pharyngeal cancer shares common risk factors with cancer in other parts of the body, physicians can play an important preventive role. Any suspicious oral lesion (ie. exophytic lesion, ulcer, white or red plaque) or lesion that persists two weeks after removal of possible causes should be further investigated.

\section{Oral health counseling}

Depending on the previously reported oral health problems and prevention principles, a Personal Care Package (PCP) may be used to provide individual oral health counseling to frail older adults and their caregivers, adapted to the level of care-dependence, socio-medical context and living conditions (Table 2). Oral health promotion counseling to caregivers who may supervise, assist or provide oral hygiene to the patient is critical. The physician may offer advice on effective communication techniques with patients with cognitive and behavioural problems when performing oral hygiene. 
Natural teeth should be brushed at least twice a day for approximately 2 minutes with a medium/soft toothbrush and fluoride toothpaste. When there is a high caries risk, the dentist may prescribe a 5000 ppm fluoride toothpaste. In patients with dexterity problems, powered toothbrushes, sonic toothbrushes or specially adapted toothbrush can be used. The interdental spaces should be cleaned once a day using dental floss (although not easily applied in patients with reduced manual dexterity), interdental brushes or jet tip oral irrigators. It is also important to clean the tongue with a soft toothbrush or tongue cleaner/ scraper to remove bacteria that cause bad breath or infections in the mouth and dentures. In bedridden patients, particularly with dysphagia, it is important to further clean the oral mucosa with a soft toothbrush or gauze to remove any food particles, debris or plaque trapped in the mouth. Mouthwashes based on chlorhexidine,${ }^{48}$ possibly diluted $50: 50$ with water to avoid a burning sensation, or essential-oils ${ }^{49}$ may be used, combined with tooth brushing, to control the amount of oral bacteria, gingival inflammation and plaque formation. Any sideeffects of chlorhexidine, including tooth staining, calculus build up, transient taste disturbance, burning sensation, and other oral mucosa effects ${ }^{48}$ should be considered in relation to the frail patient's benefit.

Dentures should be labelled to identify the owner in nursing homes and residential care. They should be brushed twice daily with a denture brush and a non-abrasive denture cleanser or liquid soap and rinsed after every meal. ${ }^{45,50}$ The combination of mechanical cleaning with daily use of chemical agents (eg. alkaline peroxide solutions) is highly recommended. ${ }^{45,50}$ When immersed in denture cleaning solutions, dentures should be stored away from the patient to avoid accidental drinking. For older individuals with difficulties brushing their 
dentures or for use in nursing homes and hospitals, ultrasonic cleaning combined with immersion in a cleanser solution may be applied. ${ }^{50}$ It is very important to remove the dentures at night for the prevention of denture stomatitis and aspiration pneumonia. ${ }^{45,51}$ When denture stomatitis is present, then both the patient and the dentures should be additionally treated with antifungal and antimicrobial medications as prescribed by the dentist. The oral mucosa of edentulous persons should also be cleaned with a soft toothbrush or gauze.

\section{Xerostomia and hyposalivation counseling}

Counseling for patients suffering from hyposalivation and xerostomia includes meticulous daily oral hygiene, use of high fluoride or other products advised by the dentist, regular dental visits, smoking cessation and dietary counseling (avoid acidic and sugary food and drinks). ${ }^{28,46,52}$ As salivary flow can be triggered by masticating, non-mixed food should be preferred whenever it can be chewed. Daily measures to alleviate symptoms include moistening the mouth with frequent water intake, using lip lubricants to protect lips from dryness, using saliva substitutes to moisten oral tissues and improve denture fit, and using saliva stimulants such as sugarless chewing gums with xylitol. ${ }^{28,52}$

\section{Dietary counseling}

The physician should offer all patients advice on healthy and unhealthy dietary habits. It is important to limit sugars, sweetened liquids, sticky foods, slowly dissolving candies, refined and processed foods, between-meal cariogenic snacks, acidic foods, and drinks including carbonated beverages, as they may

cause caries and tooth erosion. ${ }^{21}$ Very hot food and drinks should also be 
avoided as they are potentially involved in oral cancer promotion. ${ }^{47}$ After consuming acidic foods, the mouth should be rinsed with plenty of water to avoid tooth erosion. Encouraging older patients to eat more fresh fruit and vegetables, cheese, and milk may help to keep oral tissues healthy.

Older people with dentures often face chewing difficulties. Therefore, patients and caregivers should be advised on appropriate food selection and preparation, including cutting it into small portions, chopping, mashing or moistening before chewing. ${ }^{21,53}$ Medications containing sugar should be either replaced with sugar free alternatives or given at mealtimes. ${ }^{54}$

\section{Regular dental check-ups}

The physician should recommend regular dental check-ups particularly when the patient is frail and care-dependent. Dental reviews should be scheduled every 3-6 months for the dentate and partially dentate ${ }^{55}$ and every 12 months for edentulous patients. The option of domiciliary dental care should be highlighted to both patients and carers.

\section{Control of unhealthy habits}

The physician should offer advice on tobacco use cessation and limitation of harmful alcohol consumption to protect both oral and general health.

\section{Implications for Practice, Policy, and/or Research}

Oral health prevention strategies in frail older persons should be based on the principles of the Health Field Concept ${ }^{56}$ considering health as an outcome of human biology, environment, lifestyle, and health care organization. As a consequence, there is a need for multidisciplinary collaboration, recognizing 
that multiple interventions are needed to properly address the determinants of oral health in older adults.

Physicians treating older patients, particularly geriatricians, elderly care physicians and primary care physicians should be involved in oral health screening of older patients in practice, at home and in institutional care. They should understand, recognize and judge the importance of dental disease, oral pathology and functional impairment, offer oral health counseling to patients and their caregivers, manage oral conditions as appropriate, and refer patients to oral health professionals where needed.

In order to achieve an integrated approach and to promote and implement collaborative practice in geriatric oral health, it is essential that the following conditions are fulfilled: geriatric oral health programs should be developed for non-dental health care providers at all levels of education; inter-professional education should facilitate collaboration and consequently improve health outcomes in frail older people; collaborative practices must enable comprehensive services by working with patients, their (informal) caregivers and communities in order to provide the best quality and continuity of care across different care settings; inter-professional teamwork has to guarantee the level of collaboration and coordination between involved professions (e.g. physicians, nurses, dentists, dieticians, speech therapists and others) delivering patient-centred care.

As outlined in the minimum core competencies for family medicine residents ${ }^{57}$, residents are expected to be able to "individualize standard recommendations for screening tests and chemoprophylaxis in older patients based on life 
expectancy, functional status, patient preference and goals of care“. A similar "educational goal" has been published by the European Geriatric Medicine Society (EuGMS) and the European Union Specialist Section - Geriatric Medicines (UEMS-GMS) ${ }^{58}$ stating, that graduates should know about primary and community care of older patients. Very recently, EuGMS and the European College of Gerodontology (ECG) have published recommendations on learning objectives in training of non- dental healthcare professionals addressing oral health assessment and promotion of older adults. ${ }^{7}$ In this publication authors do not only address knowledge gain, but also the improvement of attitudes of staff towards oral health promotion. Changing the attitude of professionals involved in the care of older people towards more preventative care planning, will raise the need for inter- and multi-professional collaboration amongst many stakeholders. This approach emphasises the need for a life-long learning approach $^{59}$ in terms of inter-professional education and training. ${ }^{60-62}$ Improving awareness and changing the scope of practice of the health workforce in various systems will help to address the current needs of ageing societies.

\section{List of figures}

Figure 1. Oral Health Assessment Tool (OHAT) for dental screening.

Reproduced from: Chalmers JM, King PL, Spencer AJ, Wright FAC, Carter KD. The Oral Health Assessment Tool - Validity and reliability. Australian Dental Journal 2005;50:191-199, Figure 1, p. 197, Publisher: John Wiley and Sons, with permission from the Australian Dental Association.

Figure 2. Periodontal disease. A large amount of dental plaque is accumulated on the teeth surface. 
Figure 3. Oral cancer (courtesy of Professor Jan Zapała, Chair of CranioMaxillofacial, Oncological and Reconstructive Surgery, Institute of Dentistry, Faculty of Medicine, Jagiellonian University Medical College, and Ludwik Rydygier's Specialistic Hospital, Poland).

\section{Conflict of interest}

The authors declare no conflicts of interest. 


\section{References}

1. World Health Organization. World Report on Ageing and Health. Geneva, Switzerland: WHO Press, 2015. http://www.who.int/ageing/events/worldreport-2015-launch/en/. Accessed on June 15, 2018.

2. Petersen PE, Yamamoto T. Improving the oral health of older people: the approach of the WHO Global Oral Health Programme. Community Dent Oral Epidemiol 2005;33:81-92.

3. Niesten D, van Mourik K, van der Sanden W. The impact of having natural teeth on the QoL of frail dentulous older people. A qualitative study. BMC Public Health 2012;12:839..

4. Rouxel P, Tsakos G, Chandola T, Watt RG. Oral Health - A neglected aspect of subjective well-being in later life. J Gerontol B Psychol Sci Soc Sci 2018;73:382-386.

5. Haber J, Hartnett E, Allen K, et al. Putting the mouth back in the head: HEENT to HEENOT. Am J Public Health 2015;105:437-441.

6. Hummel J, Phillips KE, Holt B et al. Oral Health: An Essential Component of Primary Care. White paper, June 2015. http://www.niioh.org/sites/default/files/Oral_Health_white_paper_final.pdf. Accessed on June 15, 2018.

7. Kossioni AE, Hajto-Bryk J, Maggi S, et al. An Expert Opinion from the European College of Gerodontology and the European Geriatric Medicine Society: European Policy Recommendations on Oral Health in Older Adults. J Am Geriatr Soc 2018;66:609-1063. 
8. Friedewald VE, Kornman KS, Beck JD, et al; American Journal of Cardiology; Journal of Periodontology. The American Journal of Cardiology and Journal of Periodontology editors' consensus: periodontitis and atherosclerotic cardiovascular disease. J Periodontol 2009;80:1021-1032.

9. Azarpazhooh A, Tenenbaum HC. Separating fact from fiction: use of highlevel evidence from research syntheses to identify diseases and disorders associated with periodontal disease. J Can Dent Assoc 2012;78:c25.

10. Lockhart PB, Bolger AF, Papapanou PN, Osinbowale O et al; American Heart Association Rheumatic Fever, Endocarditis, and Kawasaki Disease Committee of the Council on Cardiovascular Disease in the Young, Council on Epidemiology and Prevention, Council on Peripheral Vascular Disease, and Council on Clinical Cardiology. Periodontal disease and atherosclerotic vascular disease: does the evidence support an independent association?: a scientific statement from the American Heart Association. Circulation $2012 ; 125: 2520-2544$.

11. Tonetti MS, Van Dyke TE; working group 1 of the joint EFP/AAP workshop. Periodontitis and atherosclerotic cardiovascular disease: consensus report of the Joint EFP/AAP Workshop on Periodontitis and Systemic Diseases. J Periodontol 2013;84(4 Suppl):S24-29.

12. Sanz M, Ceriello A, Buysschaert M, Chapple I, et al. Scientific evidence on the links between periodontal diseases and diabetes: Consensus report and guidelines of the joint workshop on periodontal diseases and diabetes by the International Diabetes Federation and the European Federation of Periodontology. J Clin Periodontol 2018;45:138-149. 
13. Scannapieco FA, Cantos A. Oral inflammation and infection, and chronic medical diseases: implications for the elderly. Periodontol 2000 2016;72:153-175.

14. Desvarieux M, Demmer RT, Rundek T, Boden-Albala B, et al; Relationship between periodontal disease, tooth loss, and carotid artery plaque: the Oral Infections and Vascular Disease Epidemiology Study (INVEST). Stroke 2003;34(9):2120-2125.

15. Polzer I, Schwahn C, Völzke H, Mundt T, et al. The association of tooth loss with all-cause and circulatory mortality. Is there a benefit of replaced teeth? A systematic review and meta-analysis. Clin Oral Investig 2012;16:333-351.

16. Madianos PN, Koromantzos PA. An update of the evidence on the potential impact of periodontal therapy on diabetes outcomes. J Clin Periodontol 2018;45:188-195.

17. Müller F. Oral hygiene reduces the mortality from aspiration pneumonia in frail elders. J Dent Res 2015;94(3 Suppl):14S-16S.

18. Sjögren $\mathrm{P}$, Nilsson E, Forsell M, Johansson $\mathrm{O}$, et al. A systematic review of the preventive effect of oral hygiene on pneumonia and respiratory tract infection in elderly people in hospitals and nursing homes: effect estimates and methodological quality of randomized controlled trials. J Am Geriatr Soc 2008;56:2124-2130.

19. van der Maarel-Wierink CD, Vanobbergen JN, Bronkhorst EM, Schols $\mathrm{JM}$, et al. Oral health care and aspiration pneumonia in frail older people: a systematic literature review. Gerodontology 2013;30:3-9. 
20. Tanaka T, Takahashi K, Hirano H, Kikutani T, et al. Oral Frailty as a Risk Factor for Physical Frailty and Mortality in Community-Dwelling Elderly. J Gerontol A Biol Sci Med Sci 2017 Nov 17. doi: 10.1093/gerona/glx225. [Epub ahead of print]

21. Touger-Decker R, Mobley C. Position of the Academy of Nutrition and Dietetics: oral health and nutrition. J Acad Nutr Diet 2013;113:693-701.

22. Huppertz VAL, van der Putten GJ, Halfens RJG, et al. Association between malnutrition and oral health in Dutch nursing home residents: Results of the LPZ Study. J Am Med Dir Assoc 2017;18:948-954.

23. Poulsen, I, Rahm Hallberg, I, Schroll, M. Nutritional status and associated factors on geriatric admission. J Nutr Health Aging 2006;10:8490.

24. Brennan LJ, Strauss J. Cognitive impairment in older adults and oral health considerations: treatment and management. Dent Clin North Am 2014:58:815-828.

25. Hybels CF, Bennett JM, Landerman LR, et al. Trajectories of depressive symptoms and oral health outcomes in a community sample of older adults. Int J Geriatr Psychiatry 2016:31:83-91.

26. Tavares M, Lindefjeld Calabi KA, San Martin L. Systemic diseases and oral health. Dent Clin North Am 2014:58:797-814.

27. Van der Putten GJ, Brand HS, Schols JM, de Baat C.The diagnostic suitability of a xerostomia questionnaire and the association between 
xerostomia, hyposalivation and medication use in a group of nursing home residents. Clin Oral Investig 2011;15:185-192.

28. Plemons J, Al-Hashimi I, Marek CL. Managing xerostomia and salivary gland hypofunction: Executive summary of a report from the American Dental Association Council on Scientific Affairs. J Am Dent Assoc $2014 ; 145: 867-873$

29. de Deco CP, Reis MRVS, Marchini AMPS, et al. Taste alteration, mouth dryness and teeth staining as side effects of medications taken by elderly. BJOS 2014:13:257-260.

30. Janssens $B$, Petrovic $M$, Jacquet $W$, et al. Medication use and its potential impact on the oral health status of nursing home residents in Flanders (Belgium). J Am Med Dir Assoc 2017;18:809.e1-809.e8.

31. Chung JP, Mojon P, Budtz-Jørgensen E. Dental care of elderly in nursing homes: perceptions of managers, nurses, and physicians. Spec Care Dentist 2000;20:12-17.

32. Andersson K, Furhoff AK, Nordenram G, et al. 'Oral health is not my department'. Perceptions of elderly patients' oral health by general medical practitioners in primary health care centres: a qualitative interview study. Scand J Caring Sci 2007;21:126-133.

33. Quijano A, Shah AJ, Schwarcz Al, et al. Knowledge and orientations of internal medicine trainees toward periodontal disease. $\mathrm{J}$ Periodontol 2010;81:359-363. 
34. Marchini L, Hartshorn JE, Cowen $\mathrm{H}$, et al. A Teaching tool for establishing risk of oral health deterioration in elderly patients: development, implementation, and evaluation at a U.S. dental school. J Dent Educ 2017:81:1283-1290.

35. Dickinson $\mathrm{H}$, Watkins $\mathrm{C}$, Leathley $\mathrm{M}$. The development of the THROAT: the holistic and reliable oral assessment tool. Clinical Effectiveness in Nursing 2001;5:104-110.

36. Kayser-Jones J, Bird WF, Paul SM, et al. An instrument to assess the oral health status of nursing home residents. Gerontologist 1995;35:814824.

37. Chalmers JM, King PL, Spencer AJ, et al. The Oral Health Assessment Tool - Validity and reliability. Aust Dent J 2005;50:191-199.

38. Schimmel M, Christou P, Miyazaki H, Halazonetis D, et al. A novel colourimetric technique to assess chewing function using two-coloured specimens: Validation and application. J Dent 2015;43:955-964.

39. GBD 2015 Disease and Injury Incidence and Prevalence Collaborators. Global, regional, and national incidence, prevalence, and years lived with disability for 310 diseases and injuries, 1990-2015: a systematic analysis for the Global Burden of Disease Study 2015. Lancet 2016;388:1545-1602.

40. Tonetti MS, Bottenberg P, Conrads G, et al. Dental caries and periodontal diseases in the ageing population: call to action to protect and enhance oral health and well-being as an essential component of healthy ageing - Consensus report of group 4 of the joint EFP/ORCA Workshop on 
the boundaries between caries and periodontal diseases. J Clin Periodontol 2017;44 (Suppl 18):S135-S144.

41. Ekstrand KR. High fluoride dentifrices for elderly and vulnerable adults: does it work and if so, then why? Caries Res 2016;50 (Suppl 1):15-21.

42. Wierichs RJ, Meyer-Lueckel H. Systematic review on non-invasive treatment of root caries lesions. J Dent Res 2015;94: 261-271.

43. Srinivasan $M$, Schimmel $M$, Riesen $M$, et al. High-fluoride toothpaste: a multicenter randomized controlled trial in adults. Community Dent Oral Epidemiol 2014;42:333-340.

44. Hendre AD, Taylor GW, Chávez EM, Hyde S. A systematic review of silver diamine fluoride: Effectiveness and application in older adults. Gerodontology 2017;34:411-419.

45. Felton D, Cooper L, Duqum I, et al. American College of Prosthodontists. Evidence-based guidelines for the care and maintenance of complete dentures: a publication of the American College of Prosthodontists. J Prosthodont 2011;20 (Suppl 1):S1-S12.

46. Gil-Montoya J A, Silvestre F J, et al. Treatment of xerostomia and hyposalivation in the elderly: A systematic review. Med Oral Patol Oral Cir Bucal. 2016;21:e355-366.

47. Petersen PE. Oral cancer prevention and control-the approach of the World Health Organization. Oral Oncol 2009;45(4-5):454-460. 
48. James $\mathrm{P}$, Worthington $\mathrm{HV}$, Parnell $\mathrm{C}$, et al. Chlorhexidine mouthrinse as an adjunctive treatment for gingival health. Cochrane Database Syst Rev 2017; 3: Art. No. CD008676.

49. Haas AN, Wagner TP, Muniz FW, et al. Essential oils-containing mouthwashes for gingivitis and plaque: Meta-analyses and meta-regression. J Dent 2016;55:7-15.

50. Papadiochou S, Polyzois G. Hygiene practices in removable prosthodontics: A systematic review. Int J Dent Hyg 2018;16(2):179-201.

51. linuma $T$, Arai $Y$, Abe $Y$, et al. Denture Wearing during sleep doubles the risk of pneumonia in the very elderly. J Dent Res 2014;94:28S-36S.

52. Furness S, Worthington HV, Bryan G, et al. Interventions for the management of drymouth: topical therapies. Cochrane Database of Systematic Reviews 2011, Issue 12. Art. No.: CD008934.

53. Kossioni A, Bellou O. Eating habits in older people in Greece: the role of age, dental status and chewing difficulties. Arch Gerontol Geriatr 2011;52(2):197-201.

54. Public Health England. Delivering better oral health: an evidence-based toolkit for prevention, London 2017

55. Tada S, Allen P F, Ikebe K, Matsuda K, Maeda Y. Impact of periodontal maintenance on tooth survival in patients with removable partial dentures. $\mathrm{J}$ Clin Periodontol 2015;42:46-53. 
56. Lalonde, M. A new perspective on the health of Canadians. Ottawa, ON: Minister of Supply and Services Canada, 1974. http://www.phacaspc.gc.ca/ph-sp/pdf/perspect-eng.pdf. Accessed on June 15, 2018.

57. Williams BC, Warshaw G, Fabiny AR et al. Medicine in the 21st century: Recommended essential Geriatrics competencies for Internal Medicine and Family Medicine Residents. J Grad Med Educ 2010; 2: 373-383.

58. Masud T, Blundell A, Gordon AL, et al. European undergraduate curriculum in geriatric medicine developed using an international modified Delphi technique. Age Ageing 2014;43(5):695-702.

59. National Academies of Sciences, Engineering, and Medicine; Division of Behavioral and Social Sciences and Education; Health and Medicine Division; Board on Health Sciences Policy; Forum on Aging, Disability, and Independence. Strengthening the workforce to support community living and participation for older adults and individuals with disabilities: Proceedings of a workshop. Washington (DC): National Academies Press (US), 2017.

60. Cole JR 2nd, Dodge WW, Findley JS, et al. Interprofessional collaborative practice: how could Dentistry participate? J Dent Educ 2018;82:441-445

61. Keijsers CJPWR, Dreher R, Tanner S.et al. The Special Interest Group Education, IPE section, EUGMS. Interprofessional education in geriatric medicine. Eur Ger Med 2016;7:306-314

62. Kossioni AE, Marchini L, Childs C. Dental participation in geriatric interprofessional education courses: A systematic review. Eur J Dent Educ 2018;22:e530-e541. 
Table 1. Six oral health-related questions to be added to a medical interview, the respective risk of rapid oral health deterioration (ROHD), and their follow-up procedures.

\begin{tabular}{|c|c|c|}
\hline $\begin{array}{l}\text { Oral health-related } \\
\text { question }\end{array}$ & Follow-up procedure & $\begin{array}{l}\text { Risk of } \\
\text { ROHD }\end{array}$ \\
\hline $\begin{array}{l}\text { Is there anything } \\
\text { bothering you in your } \\
\text { mouth? }\end{array}$ & $\begin{array}{l}\text { YES - Oral exam and/or referral to a dentist } \\
\text { NO* }\end{array}$ & $\begin{array}{c}\text { Increased } \\
-\end{array}$ \\
\hline $\begin{array}{l}\text { Do you feel your } \\
\text { mouth dry? }\end{array}$ & $\begin{array}{l}\text { YES- Review medical history; review medication list for possible changes } \\
\text { to reduce xerostomic effects; consider non-pharmacological and } \\
\text { pharmacological interventions; oral exam and/or referral to a dentist } \\
\text { NO* }\end{array}$ & $\begin{array}{c}\text { Increased } \\
-\end{array}$ \\
\hline $\begin{array}{l}\text { Do you have natural } \\
\text { teeth, dentures or } \\
\text { both? }\end{array}$ & $\begin{array}{l}\text { Answer to this question will guide the way next three questions should be } \\
\text { formulated }\end{array}$ & \\
\hline $\begin{array}{l}\text { How often do you } \\
\text { brush your } \\
\text { teeth/denture(s)? }\end{array}$ & $\begin{array}{l}\text { Dentate with or without dentures } \\
<1 / \text { day- Counseling on daily care; then oral exam and decision on dental } \\
\text { referral } \\
\geq 1 / \text { day- Review oral care practices and offer counseling* } \\
\text { Edentulous wearing complete dentures } \\
<1 / \text { day- Counseling to improve frequency; then oral exam and decision } \\
\text { on dental referral } \\
\geq 1 / \text { day- Check the denture and consider counseling for improvements on } \\
\text { cleaning if visibly soiled }{ }^{*}\end{array}$ & $\begin{array}{c}\text { Increased } \\
- \\
\text { Increased } \\
-\end{array}$ \\
\hline $\begin{array}{l}\text { (If dentate) Do your } \\
\text { gums bleed on } \\
\text { brushing, eating or } \\
\text { spontaneously? }\end{array}$ & $\begin{array}{l}\text { YES - Oral exam and/or referral to a dentist } \\
\text { NO* }\end{array}$ & $\begin{array}{c}\text { Increased } \\
-\end{array}$ \\
\hline $\begin{array}{l}\text { Did you have a dental } \\
\text { visit in the past } 12 \\
\text { months? }\end{array}$ & $\begin{array}{l}\text { YES* } \\
\text { NO- Oral exam and/or referral to a dentist }\end{array}$ & Increased \\
\hline
\end{tabular}

* A further initial oral health assessment is recommended in all older patients, irrespective of their answers to the questionnaire, followed by a decision on the need for dental referral. 
Table 2. Oral health counseling for older patients and their caregivers offered by the physician in practice, at home and in institutional care. Oral care advice should be adapted to the individual's needs in collaboration with the dentist.

The natural teeth should be brushed at least twice a day for approximately 2 minutes with a medium/soft toothbrush and fluoride toothpaste. If brushing with a manual toothbrush is difficult, a powered or sonic toothbrush can be used. The interdental spaces should be cleaned once a day.

The dentures should be brushed at least twice a day with a non-abrasive denture cleanser or liquid soap (don't use a dentifrice). Mechanical cleaning should be combined with chemical cleansing agents.

The dentures should be removed at night and stored in water with a denture cleanser solution, unless otherwise advised by the dentist.

The oral mucosa of edentulous individuals should be rinsed with plenty of water after meals to remove any remaining food particles and/or cleaned with a soft toothbrush or gauze.

The toothbrush and denture-brush should be left to air dry.

The tongue should be cleaned on a daily basis.

Individuals with severe tooth loss and denture wearers should receive appropriate food selection and preparation counseling to improve masticatory function, dietary and nutritional intake.

Dentate adults should limit sugar-containing, refined and processed foods, between-meal cariogenic snacks, acidic foods and drinks, and carbonated beverages to protect the natural teeth from dental caries and erosion. After consuming acidic foods and drinks the mouth should be rinsed with plenty of water.

Advice should be offered on smoking cessation and limiting alcoholic beverages. Appropriate preventive and palliative advice should be offered to individuals with hyposalivation/ xerostomia.

Regular dental visitations should be scheduled every 3-12 months. The individualized dental appointments' schedule will be advised by the dentist. 


\section{Figure 1}

\begin{tabular}{|c|c|c|c|c|}
\hline \multicolumn{4}{|c|}{ Completed by } & \multirow{2}{*}{$\begin{array}{l}\text { Date }-1-C- \\
\text { ory } \\
\text { osdent }\end{array}$} \\
\hline & \multicolumn{3}{|c|}{ 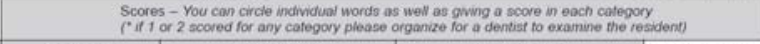 } & \\
\hline Catogary & $0=$ heaithy & $1=$ changes $^{\circ}$ & $2=$ unhealtty & Category scotes \\
\hline Lips & smoosh, pink, moist & dry, chapped, \& red at comers & $\begin{array}{l}\text { Swelling or lump, whitarediucerated } \\
\text { patch, bleeding ilicerated at corners }\end{array}$ & \\
\hline Tongue & $\begin{array}{l}\text { normal, moist } \\
\text { roughness, pink }\end{array}$ & patchy, fissured, red, cooted & $\begin{array}{l}\text { patch that is red andior whiee, } \\
\text { ulcerated, swollen }\end{array}$ & \\
\hline Gums and tissues & $\begin{array}{l}\text { pink, moist, smooth, } \\
\text { no blooding }\end{array}$ & $\begin{array}{l}\text { diny, shiny, rough, red, swollen, one } \\
\text { uicorisore spot under dentures }\end{array}$ & $\begin{array}{l}\text { Swollen, bleeding, uicers, whiteired } \\
\text { patchins, gonoratizod rodiness } \\
\text { under dentures }\end{array}$ & \\
\hline Salva & $\begin{array}{l}\text { moist tissues, watery } \\
\text { and free flowing } \\
\text { saliva }\end{array}$ & $\begin{array}{l}\text { dry, sticky tissues, intle salva } \\
\text { present, resident thinks they } \\
\text { have a dry mouth }\end{array}$ & $\begin{array}{l}\text { tissues parched and red, } \\
\text { very littieno saiva present, saliva } \\
\text { is thick, resident thinks they have } \\
\text { a dry mouth }\end{array}$ & \\
\hline $\begin{array}{l}\text { Natura leoth } \\
\text { Yes } N_{0}\end{array}$ & $\begin{array}{l}\text { no decayed of } \\
\text { broken leethroots }\end{array}$ & $\begin{array}{l}\text { 1.3 decayed of broken leeth } \\
\text { roots or very worn down leeth }\end{array}$ & $\begin{array}{l}4 \cdot \text { decayed or bohen teethiroots, } \\
\text { or very worn down teeth, ot } \\
\text { less than } 4 \text { leeth }\end{array}$ & \\
\hline $\begin{array}{l}\text { Dentures } \\
\text { Yes } \text { No }_{0}\end{array}$ & $\begin{array}{l}\text { no broken areas of } \\
\text { teeth, dentures } \\
\text { regulary wom, and } \\
\text { namined }\end{array}$ & $\begin{array}{l}1 \text { broken areahtooth or dentures } \\
\text { only worn for } 1.2 \text { hrs dality. } \\
\text { of dentureses not named. } \\
\text { or loose } \\
\end{array}$ & $\begin{array}{l}\text { more than } 1 \text { broken areatooth, } \\
\text { denture minsing or not worn, bose } \\
\text { and needs denture adhesive. } \\
\text { or not named }\end{array}$ & \\
\hline Oral cleaniness & $\begin{array}{l}\text { clean and no food } \\
\text { particles or tartar in } \\
\text { mouth or dentures }\end{array}$ & $\begin{array}{l}\text { food particlestartariploquo } \\
\text { in } 1-2 \text { areas of the mouth or on } \\
\text { small area of dentures of halitosis } \\
\text { (bad breath) }\end{array}$ & $\begin{array}{l}\text { food particlestartariphaque in most } \\
\text { areas of the mouth or on most of } \\
\text { dentures or sovere halitosis } \\
\text { (bad breath) }\end{array}$ & \\
\hline Dental pain & $\begin{array}{l}\text { no behowoural, verbal, } \\
\text { or physical signs of } \\
\text { dertal pain }\end{array}$ & $\begin{array}{l}\text { ate verbal } 8 \text { or behavioural } \\
\text { signs of pain such as } \\
\text { pulling at face, chewing } \\
\text { lips, not eating, aggression }\end{array}$ & 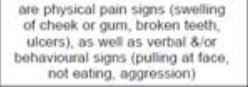 & \\
\hline \multicolumn{4}{|c|}{ 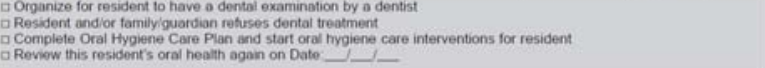 } & $\begin{array}{l}\text { TOTAL } \\
\text { SCORE } \overline{16}\end{array}$ \\
\hline
\end{tabular}

\section{Figure 2}

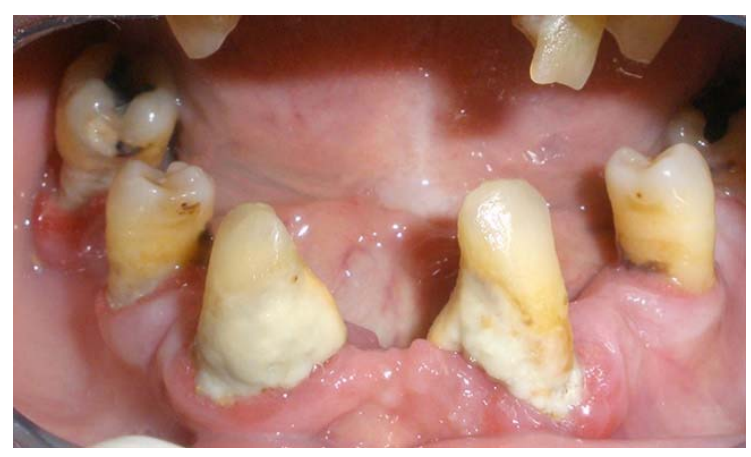

\section{Figure3}

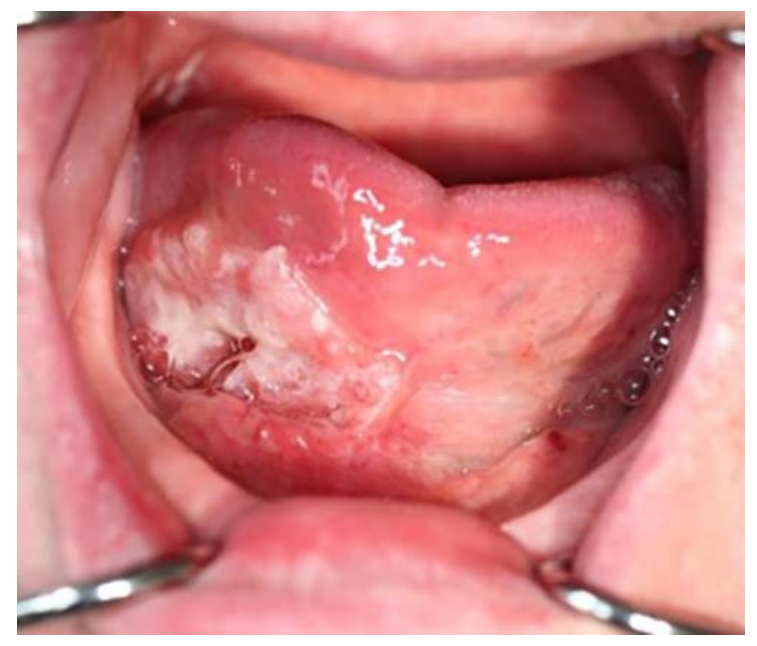

